\title{
Development of hydraulic low frequency marine seismic vibrator
}

\author{
Hiroaki OZASA ${ }^{1}$, Hitoshi MIKADA ${ }^{2}$, Fumio SATO ${ }^{1}$, Fumitoshi MURAKAMI ${ }^{3}$, \\ Junichi TAKEKAWA ${ }^{2}$ and Eiichi ASAKAWA ${ }^{3}$ \\ ${ }^{1}$ IHI Corporation \\ ${ }^{2}$ Dept. Civil and Earth Resources Eng., Kyoto University \\ ${ }^{3}$ Innovative Technology Dept., JGI, Incorporated
}

\begin{abstract}
We have fabricated an underwater vibratory seismic source with the scale of $60-70 \%$, to the real design for towed marine seismic vibrator (MSV) using hydraulic servo system. Several evaluation tests were conducted in the sea using the downsized MSV at a depth of about $250 \mathrm{~m}$ in water. The performance of the downsized MSV was tested for maximum sound level, frequency characteristic, horizontal directivity, and vertical directivity of the sound field generated from the downsized MSV in Suruga Bay about $100 \mathrm{~km}$ away from Tokyo. The sound source level and the frequency characteristic were equal to or higher than the estimated specification between $3 \mathrm{~Hz}$ and $300 \mathrm{~Hz}$. The intensities of the generated sound fields observed at vertical and horizontal directions were equivalent to each other, which indicate that the generated sound field could be regarded almost omnidirectional. A trial seismic survey using a short streamer was also conducted and a shot gather was acquired with several different conditions in sweep frequency bands and in sweep lengths. The results showed that the downsized MSV could perform well to be deployed as a marine seismic source in shallow water surveys and that MSV would be a versatile source as one of alternatives to the existing impulsive seismic sources in practice such as airguns, waterguns, boomers, etc.
\end{abstract}

\section{INTRODUCTION}

The quest of earth natural resources below the seafloor, seismic methods are frequently applied for exploration and for development. Since seismic methods require seismic signals, artificial sources such as airguns, waterguns, boomers, etc. are used as active sources that generates seismic signals. In particular, airguns originally designed to provide a sharp pressure pulse of relatively broad frequency ${ }^{1)}$ are mostly deployed for its simplicity in the mechanism and functional reliability. However, the industry is being asked to reduce the perceived impact these impulsive seismic sources could cause in the marine environments ${ }^{2}$. The principal issue with respect to using impulsive sources to acquire seismic data is the amount and nature of the acoustic energy being emitted into the marine environment, which may cause the death of marine mammals in the worse case scenario ${ }^{2)}$.

In land seismic surveys, the use of vibratory seismic sources was proposed ${ }^{3)}$ and has been in practice since long time ago. Such vibratory seismic sources have been used to assure the security and safety in land operations without resorting to the use of explosives such as dynamites near urban areas or for the environmental protection in the suburb. Accordingly, marine seismic vibrators have been proposed ${ }^{4,5)}$ but have not come well into use due to the convenience of the other impulsive sources in the marine environment. There are two major source mechanisms to emit acoustic signals in the current vibratory source development: one is electromagneticaly-deriven oscillator ${ }^{5)}$ and the other Helmholtz resonator ${ }^{6}$. Marine seismic vibrators could surely reduce the impact to the marine environment but need to satisfy the conditions of both the controllability and the repeatability in amplitude and phase for high quality measurements.

We designed Marine Seismic Vibrator (MSV) as a new type marine vibratory seismic source that satisfy the above conditions. We employed the hydraulic servo system ${ }^{7)}$ for the conditions in phase and in amplitude. A scaled MSV was fabricated to verify the feasibility of MSV as marine vibratory seismic source, and was used to conduct a field test to evaluate if the system was designed to perform as planned, if omnidirectional radiation patterns would be achieved, and if the source could be used for a seismic reflection survey or not, etc. Our sea trial has shown the feasibility of the system to be used as a marine vibratory source that could be an alternative to the current airgun source working in practice. 


\section{EXPERIMENT METHOD}

\section{(1) Source characteristic examination}

The source characteristic examination was conducted at Suruga-bay Japan in Sep 2014. The test was carried out at a depth of $250 \mathrm{~m}$ approximately in the ocean. The performance such

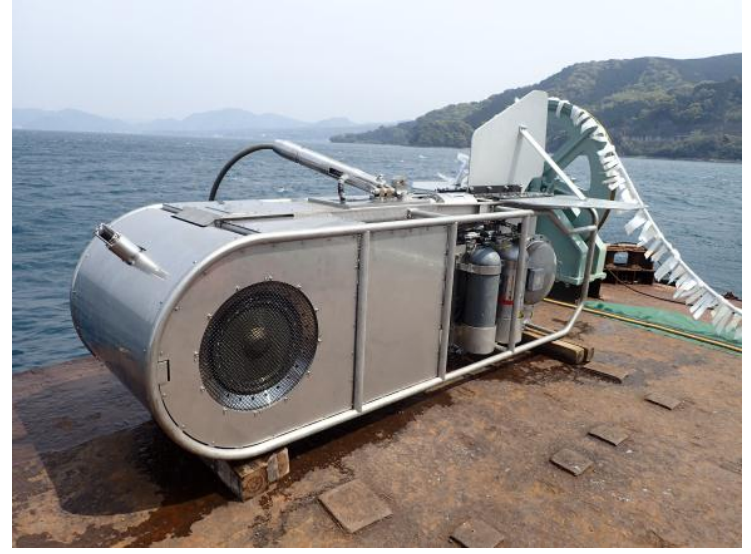

Figure 1 A photo of downsized Marine Seismic Vibrator (MSV)

as maximum sound level, frequency characteristic, horizontal directivity, and vertical directivity of the sound field generated from downsized MSV was examined as a field experiment. Figure 2 shows the layout of the source characteristic examination. In the examination, the downsized MSV oscillated sine wave. The distance between the source and a monitor hydrophone was 1 meter.

\section{(2) Seismic survey trial}

Seismic survey trial using a short streamer was also conducted following the source characteristic examination. Figure 3 shows the layout of the seismic survey trial. In this trial, the barge was at

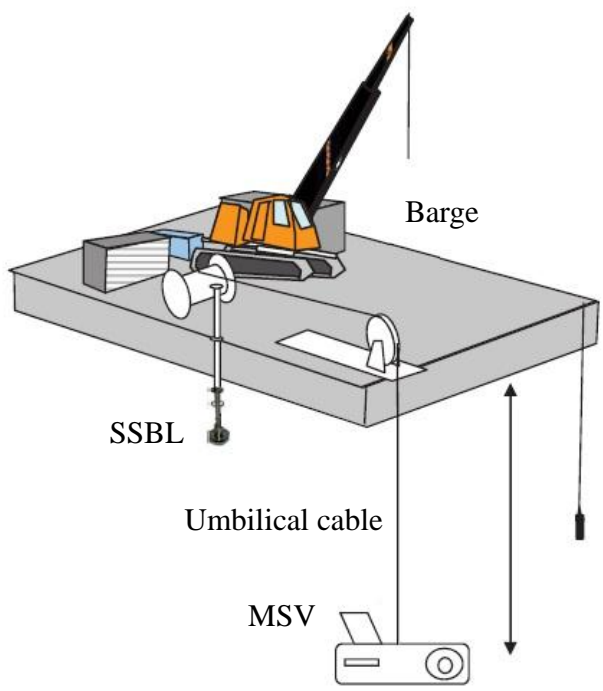

Figure 2 Layout of the source characteristic examination

anchor, some shot gathers were acquired by several emission patterns with different frequency bands in the trial. Emission patterns used in the trial are shown in Table 1. Each emission patterns was designed to equalize the intensity through its frequency range. Figure 4 shows the frequency versus the intensity of input emission pattern 1 .

Table 1 Emission pattern

\begin{tabular}{|c|c|c|c|}
\hline No. & Waveform & $\begin{array}{c}\text { Duration } \\
\text { Time (s) }\end{array}$ & $\begin{array}{c}\text { Frequency } \\
\text { range (Hz) }\end{array}$ \\
\hline Pattern 1 & Sweep & 4 & 7 to 100 \\
\hline Pattern 2 & Sweep & 4 & 7 to 28 \\
\hline Pattern 3 & Sweep & 4 & 25 to 100 \\
\hline
\end{tabular}

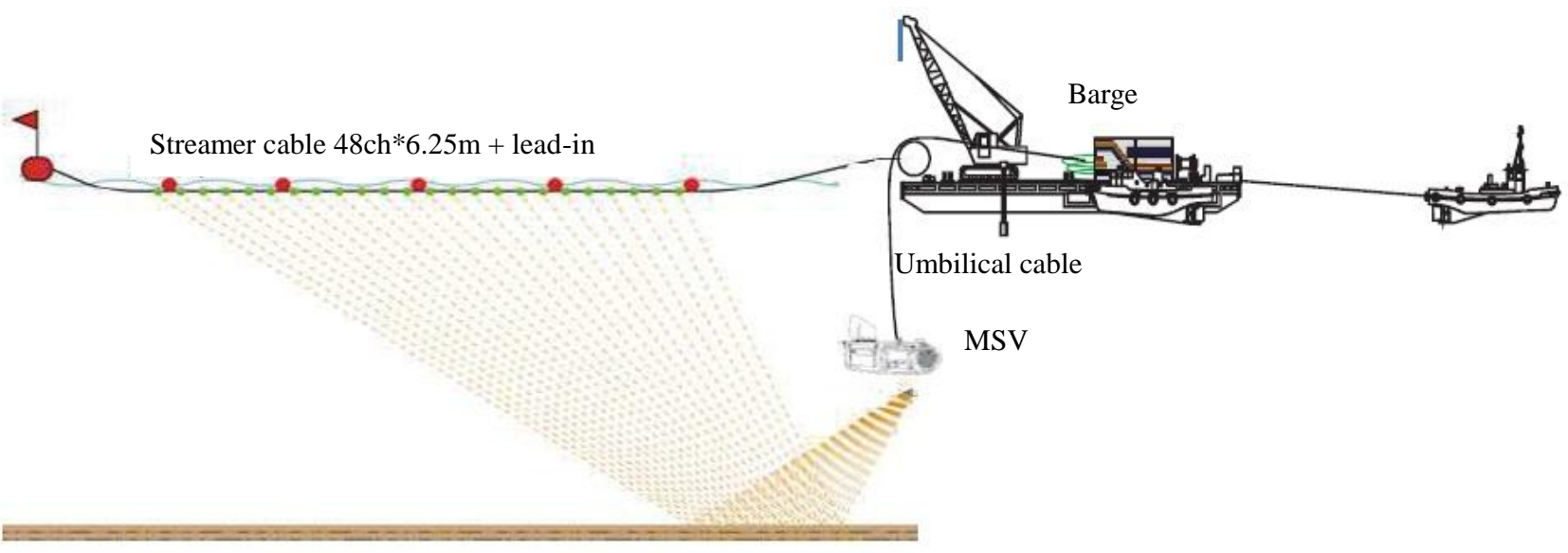

Figure 3 Layout of the seismic survey trial 


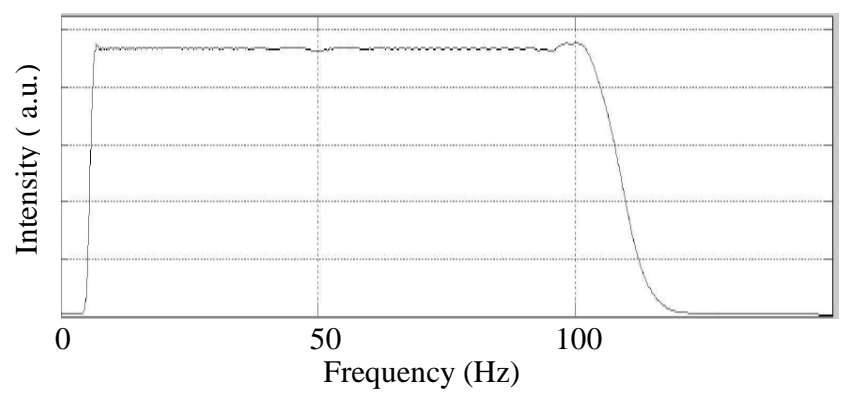

Figure 4 Frequency versus Intensity of emission pattern 1

\section{EXPERIMENT RESULTS}

\section{(1) Source characteristic examination}

Figure 5 Figure 6, Figure 7 and Figure 8 show the result of the source characteristic examination. Figure 5 shows the maximum sound level. It was equal to or higher than the estimated specifications. Figure 6 shows the frequency characteristic. According this result, the downsized MSV has nearly flat and high frequency response between 10 and $300 \mathrm{~Hz}$. Figure 7 shows the vertical directivity of the sound field generated from the downsized MSV. Figure 7 (a) shows the horizontal directivity when the oscillation frequency was $10 \mathrm{~Hz}$. Figure 7 (b) shows it when the frequency was $100 \mathrm{~Hz}$. Figure 8 also shows the vertical directivity. Figure 8 (a) shows the vertical directivity when the oscillation frequency was $10 \mathrm{~Hz}$. Figure 8 (b) shows it when the frequency was $100 \mathrm{~Hz}$. These results indicate that the generated sound field could be regarded nearly omnidirectional. From these results, the downsized MSV has equal to or higher performance than the estimated specifications. Besides, it is possible to consider that the downsized MSV is able to control the emission pattern precisely through the frequency range the source has high frequency response, under $300 \mathrm{~Hz}$. And it is also possible to consider the downsized MSV as a point sound source.

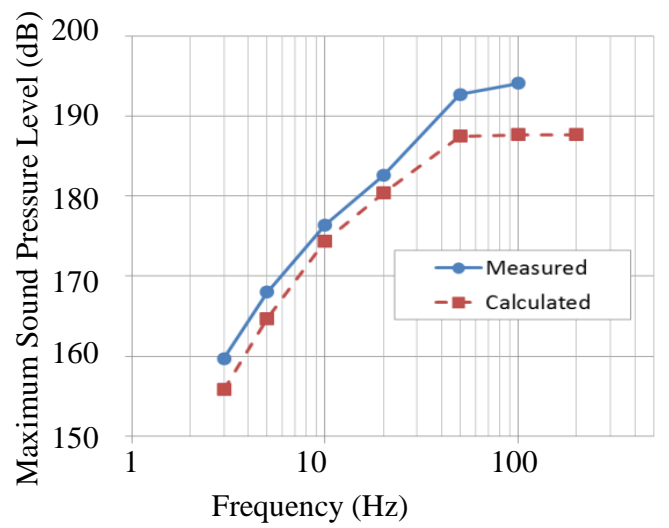

Figure 5 Maximum sound level of downsized MSV

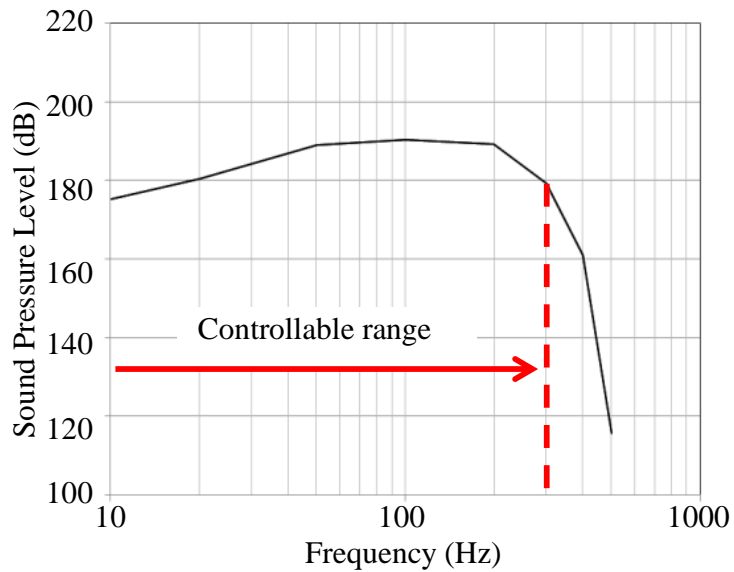

Figure 6 Frequency characteristic of downsized MSV

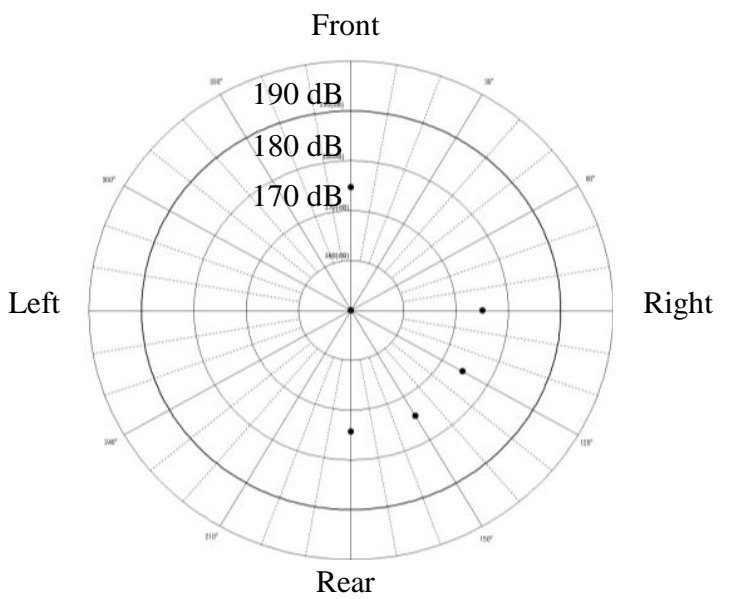

Figure 7 (a) Horizontal Directivity at $10 \mathrm{~Hz}$

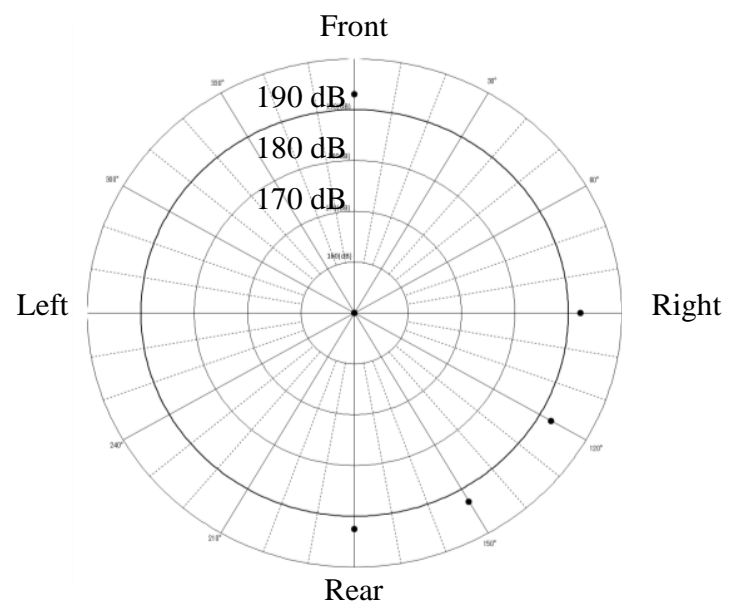

Figure 7 (b) Horizontal Directivity at $100 \mathrm{~Hz}$

\section{(2) Seismic survey trial}

Shot gathers which were acquired by several emission patterns with different frequency bands are shown in Figure 9. The cross-correlated processing was conducted between the input emission waveform and received signal. From these results, it is possible to say that MSV is able to use 
as marine seismic source as well as common impulsive seismic source by cross-correlated processing.

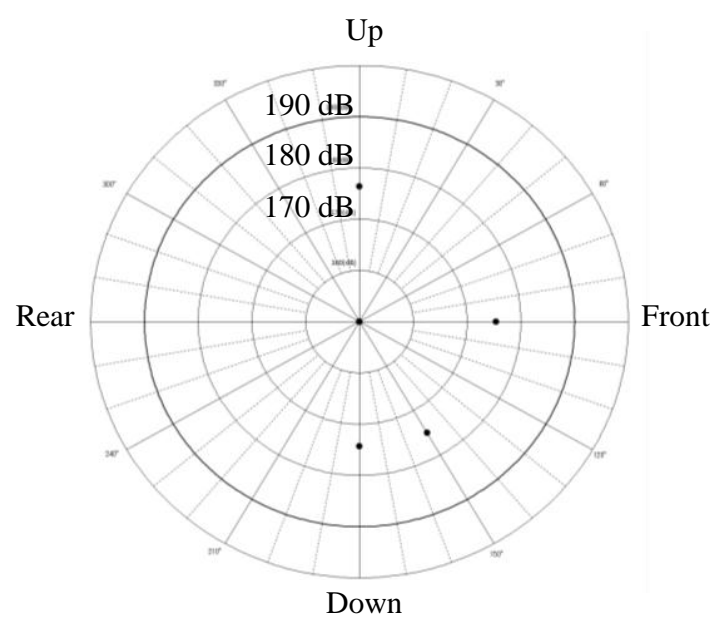

Figure 8 (a) Vertical Directivity at $10 \mathrm{~Hz}$

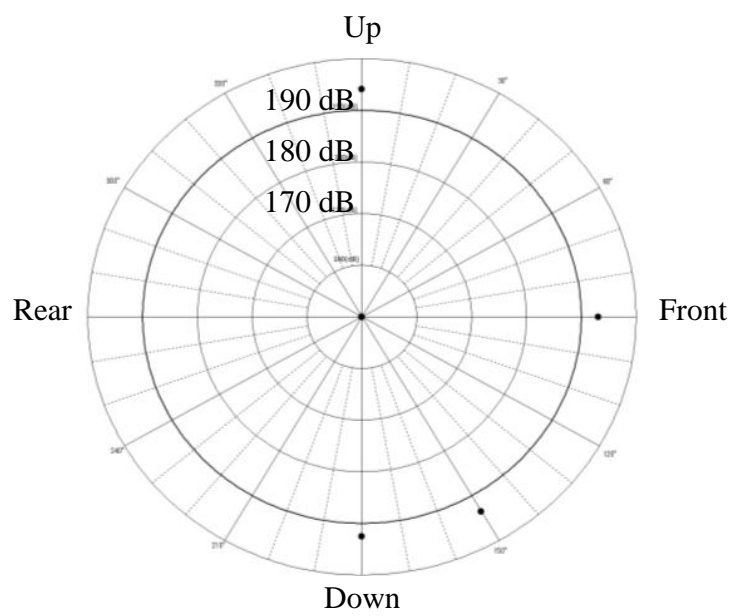

Figure 8 (b) Vertical Directivity at $100 \mathrm{~Hz}$
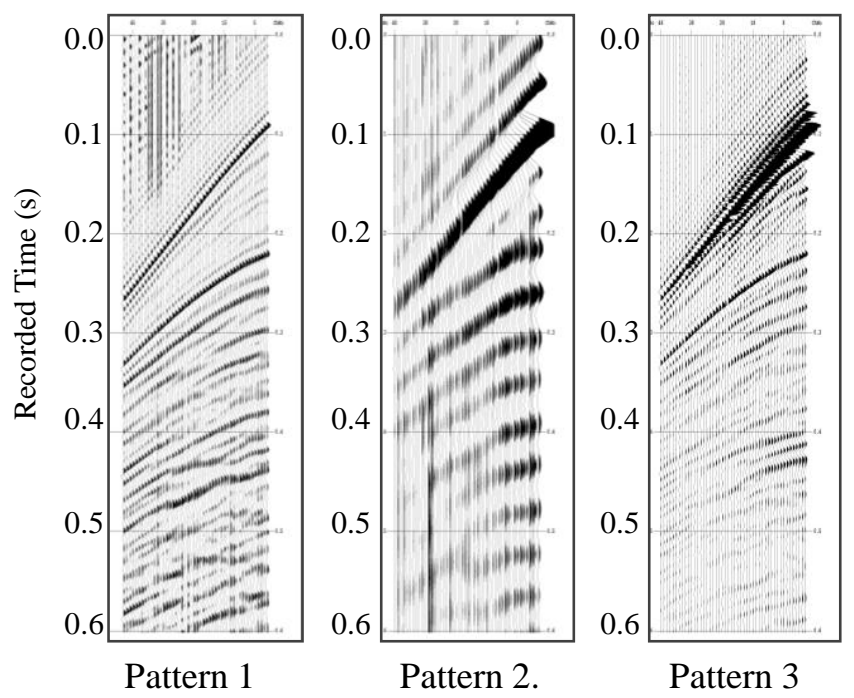

Figure 9 Shot gather acquired in seismic survey trial

\section{CONCLUSION}

The performance of a downsized MSV as a marine vibratory seismic source was verified. The downsized MSV has equal to or higher performance than the estimated specifications in the intensity of generated signals, The radiation pattern from the downsized MSV is omnidirectional. The frequency contents and the phase of the generated signals have shown the perfect controllability of the system. The seismic survey trial, we verified that the downsized MSV could produce a common shot gather that is similar to what we could obtain using airgun. Our study indicated that MSV could be a seismic vibratory source as a alternative to airgun to conduct seismic reflection surveys.

\section{REFERENCES}

1) Goertz, A., Fredrik, J., Drossaert, W. F., and Ali, J., Environmental source modelling to mitigate impact on marine life, First Break, 31 (11), 59-64.

2) B. Pramik (2013): Marine Vibroseis: shaking up the industry, First Break, 31 (11), 67-72.

3) Crawford, J. M., Doty, W. E. N. and Lee, M. R., (1960): Continuous signal seismograph, Geophysics, 25, 95-105. doi: 10.1190/1.1438707

4) Broding, R., Hess, J., and Wanous, R. (1971) A High-Power Computer-Controlled Marine Vibroseis System. IEEE Trans. Geoscience Electronics, $\quad \mathbf{9}, \quad 90-95 . \quad$ doi: 10.1109/TGE.1971.271472

5) Feng, S., Bin, C.Z., and Jun, L. (2009): Vibration Controller of Marine Electromagnetic Vibrator, Proc. ICMTMA '09. International Conference on Measuring Technology and Mechatronics Automation, 1, 926 - 929. doi: 10.1109/ICMTMA.2009.491

6) Wood, W.T., and Gettrust, J.F. (2002): New developments in deep-towed seismic acquisition, Proc. OCEANS '02, 2, 1139-1142. doi: 10.1109/OCEANS.2002.1192126

7) Sonehara M., Mutoh M., Hayasaka A., and Sato F. (2003): Exploratory development of low frequency hydraulic-type sound source, $J$. Marine Acoust. Soc. Jpn., 30 (1), 35-40. 